\title{
Seios, anseios e perdas: o corpo feminino e o câncer de mama como alvo de investimentos subjetivos
}

\author{
Breasts, longing and loss: the female body and breast cancer as the target of subjective investments \\ Iana Miranda Gorito da Rocha ${ }^{1}$, Paulo Cesar Toledo de Almeida ${ }^{2}$, Juliana Fernandes de Souza \\ Ribeiro ${ }^{3}$.
}

Como citar esse artigo. Rocha IMG, Almeida PCT, Ribeiro JFS. Seios, anseios e perdas: o corpo feminino e o câncer de mama como alvo de investimentos subjetivos. Revista Mosaico. 2013 Jan./Jun.; 04 (1): 05-10.

\begin{abstract}
Resumo
O presente estudo tratou de aspectos que envolvem a feminilidade, relevando a importância do seio como símbolo desta, além de procurar compreender o papel das representações que envolvem o corpo da mulher, reconhecendo a supervalorização desse corpo na sociedade contemporânea. Identificaram-se as particularidades que envolvem o câncer de mama, as repercussões biopsicossociais da doença, incluindo a mastectomia, suas consequências biológicas e psicológicas para a mulher que se depara com uma nova realidade. Nesse contexto, tornou-se necessário considerar a atuação do psicólogo no cuidado oncológico, com o papel de facilitador da comunicação entre os profissionais, o paciente e a família, que visa melhorar a qualidade de vida dessas pacientes. Palavras-chave: Feminilidade. Câncer de mama. Psicologia oncológica.
\end{abstract}

\begin{abstract}
This study dealt with aspects involving femininity, emphasizing the importance of the breast as a symbol of this, and seek to understand the role of representations involving the woman's body, recognizing the overvaluation of that body in contemporary society. They identified the particularities involving breast cancer, biopsychosocial impact of the disease, including mastectomy, their biological and psychological consequences for a woman who is faced with a new reality. In this context, it has become necessary to consider the psychologist in cancer care, the role of facilitated communication among professionals, patients and family, aimed at improving the quality of life of these patients. Keywords: Femininity. Breastcancer. Oncologypsychology.
\end{abstract}

\section{Que corpo é este?}

Este trabalho aborda questões em torno da feminilidade, enfocando o seio como um de seus símbolos principais. Para tanto, discute o papel das diversas formas pelas quais o corpo feminino vem sendo representado na sociedade contemporânea. Por um lado, é um alvo de cuidados especiais. Por outro, o espaço do exagero, tanto no que diz respeito à saúde, quanto em sua banalização. É um corpo erotizado e representado com jovem, o próprio ideal onde a felicidade pode existir, desde que seja uma felicidade atravessada pelo consumismo. De acordo com Costa (2004, p.190), "Ser jovem, saudável, longevo e atento à forma física tornouse a regra científica que aprova ou condena outras aspirações à felicidade".

\section{Corpo do desejo}

A mulher em si e a sua feminilidade foram bem delineadas pelos exageros e faltas ao longo dos tempos $\mathrm{e}$, tomando como referência a teoria psicanalítica e a sua compreensão do inconsciente, é possível abordar as representações do corpo feminino e as suas configurações atuais, considerando que a imagem corporal fala através do inconsciente. Nesse sentido, "o corpo que interessa à Psicanálise não é um corpo de carne e osso, mas um corpo tomado como um conjunto de elementos significantes" (NÁSIO, 1993, p.149).

Para Freud(1914/1996), o sujeito deve reconhecer sua falta e fraqueza diante das frustrações sociais, para que consiga se adequar a um modelo externo, e precisa abandonar os ideais onipotentes do ego ideal.

1. Aluna do Curso de Graduação em Psicologia da Universidade Severino Sombra (USS).

2. Mestre em Psicologia pelo PPGPS/UERJ, Professor Substituto da UFF/Volta Redonda e Professor Assistente II do Curso de Psicologia da USS.

3. Mestre em Ensino de Ciências da Saúde pela UNIPLI e Professora Assistente II do Curso de Psicologia da USS. 
Desse modo, o sujeito se diferencia dos outros. Nesse ponto, não pela sua subjetividade, mas pelo objeto que consegue consumir, ou melhor, pelo corpo que consegue apresentar e representar. O corpo vem se tornando um espaço único de propriedade, ideal de felicidade e beleza. Tal trajetória da mulher se dá desde criança e se estende por toda sua vida. Freud (1933/1996) ainda mostra ser uma passagem complexa, para a menina, o seu percurso à feminilidade, ou seja, não se trata de uma questão puramente biológica.

A construção freudiana da sexualidade tem sua origem nos "Três ensaios sobre a teoria da sexualidade", publicado em 1905. Ele fundamenta essa concepção da sexualidade através da pulsão, que, por primazia, é de ordem sexual. Para o autor, a sexualidade é construída durante as primeiras experiências afetivas do bebê. Quando nasce, a percepção do bebê é sensorial. Todo contato com seus pais ou cuidadores passa a compor as primeiras sensações sexuais e será a base para a construção dos vínculos afetivos e do desejo de aprender. É pela boca que começará a provar e a conhecer o mundo. É pela boca que fará sua primeira e mais importante descoberta afetiva: o seio. O seio é o primeiro objeto de ligação infantil. É o depositário de seus primeiros amores e ódios (FREUD, 1905/2006, p. 186).

$\mathrm{O}$ seio, na obra freudiana, está relacionado à amamentação e ao modelo de experiência de prazer que ele proporciona ao longo da vida. É visto como símbolo da feminilidade, manifestando deslumbramento e erotismo. "O seio é para o bebê objeto de suas pulsões e de autoconservação, bem como das pulsões sexuais" (TEDESCO, 2007 p.190). Dessa forma, o seio é um representante das experiências do ser humano, principalmente da mulher, porque é esta quem vê o próprio seio se desenvolvendo, junto com seus afetos.

O mamar da criança, no olhar de Bastos (1998, p.77), está para além da simples alimentação física: a criança "mama muito mais que o leite da mãe, mama as fantasias coloridas de afeto e a linguagem da mãe". Essa relação com a mãe é perpassada pela primeira relação de prazer originário da criança, é na amamentação que ela busca reviver a satisfação e reforça o laço afetivo com a mãe.

Um conceito psicanalítico importante nessa problemática é o de castração, que se instala diferentemente em termos de gênero. A percepção da diferença anatômica entre meninos e meninas gera certas fantasias. Portanto, a castração se estabelece em termos de linguagem. Se o menino a teme porque antecipa, simbolicamente, uma punição paterna, a menina fantasia uma amputação em si mesma. Desse modo, a castração, para a menina, representa um marco importante na estruturação da feminilidade. Trata-se de um fato consumado. Ela já nasce com essa ferida narcísica, registrada no próprio corpo. Enquanto nos meninos, o complexo de Édipo é destruído pelo complexo de castração, nas meninas ele se faz possível e é introduzido por meio do complexo de castração: "[...] ele inibe e limita a masculinidade e incentiva a feminilidade" (FREUD, 1925/1995, p. 318). Na angústia de renunciar ao objeto de amor da mãe e o prazer clitoriano é que a menina terá acesso à feminilidade.

Seria, então, na fase pré-edipiana que a criança aprende a amar e se sente amada, e esse período é importantíssimo para o desenvolvimento sexual e afetivo da criança. É uma etapa necessária também para que se chegue ao caminho da feminilidade, onde a menina ama sua mãe e a si, na mesma condição feminina, para que possa ser amada pelo pai, e, posteriormente, por um homem na fase adulta, sendo essa a forma na qual ela se torna mulher.

A feminilidade compõe o corpo da mulher, seus anseios sexuais, seu sofrimento psíquico. A dimensão simbólica no feminino reflete sobre os caminhos subjetivos a partir da castração, na qual a menina entra em contato com a sua feminilidade. Dessa forma, a feminilidade nos leva a compreender o sujeito, diante da sua angústia originária, marcada pela incompletude.

A feminilidade acontece a partir do momento em que a castração é significada. Há uma imagem corporal sendo modificada, há um real de corpo que remete à castração feminina, tentando se equilibrar nas faltas simbólicas. A dimensão simbólica no feminino reflete sobre os caminhos subjetivos a partir da castração, na qual a menina entra em contato com a sua feminilidade.

\section{Corpo ético e estético}

Prommier (1986) considera o feminino uma incógnita e coloca a estética como algo rudimentar na vida da mulher. Para ele, a castração revela as articulações éticas e estéticas que podem ser consideradas como identidade feminina reconhecida pelo padrão cultural. $\mathrm{Na}$ contemporaneidade, frente à própria castração, todos consumimos cada vez mais coisas com a finalidade de saciar os nossos desejos, já que somos incapazes de renunciar ao gozo originário. A cultura investe na condição fálica, levando o sujeito a buscar sua completude ilusória.

Os padrões culturais atravessam os corpos femininos, que não permanecem intactos aos múltiplos sentidos, desejos e injunções históricas. Dessa forma, um corpo é uma expressão singular em que a possibilidade de mudança é constante. A preocupação contemporânea com a estética corporal é exacerbada, como um culto ao corpo, no qual sua imagem varia conforme certas marcas identitárias: gênero, faixa etária, etnia, nacionalidade etc. O discurso veiculado pela mídia tem um papel especial nesse processo e na difusão de padrões de beleza. Define-se uma estética 
corporal através de diversas manifestações, na busca de uma imagem que ultrapasse uma certa falta. A busca ocidental de uma imagem idealizada como rica em sensualidade - um corpo feminino desejado, alvo de interesses sexualizados - leva a uma série de práticas e performances vinculados a um individualismo, expresso na noção de autoestima.

A beleza feminina está ligada à autoestima e à identidade. As imagens publicitárias vêm se apoiando nisso para estimular o gozo que se consome na própria imagem trazendo a ilusão de uma vida realizada quando se "constata" no outro um corpo perfeito, dentro dos padrões estipulados pela sociedade contemporânea. Esse padrão fez o corpo da mulher se transformar em lugar de investimento social e subjetivo, que precisa ser cuidado ou modificado. Nas palavras de Del Piore (2000, p.14), "as noções de feminilidade e corporeidade sempre estiveram, portanto, muito ligadas em nossa cultura".

As preocupações das mulheres em corrigir ou minimizar as imperfeições corporais são parte fundamental dessa sociedade que estipula um padrão de beleza como valor imprescindível. Ou se está neste padrão, ou se está relegada à condição de alijada do desejo. "No decorrer do século XX a mulher se despiu. O nu na mídia, na televisão, nas revistas e nas praias, incentivou o corpo a desvelar-se em público, banalizando-se sexualmente". (DEL PRIORE, 2001, p.99).

Segundo Le Breton (2003), a cirurgia estética não abrange somente a perspectiva física, mas alcança a parte subjetiva e imaginária. A cirurgia estética tornouse tão habitual, que a anatomia passa a ser modelável, podendo ser sempre modificada, sujeita a correções ou retoques. Dessa forma, ao mudar algo em seu corpo, o sujeito muda não só sua forma de se apresentar aos outros, mas também o olhar sobre si mesmo, delimitando sua história de vida à imagem corporal.

Algumas partes específicas do corpo feminino são privilegiadas pela sociedade, como: os seios, o cabelo, a boca e a pele. Tomando os seios como expressão corporal da feminilidade, como discutido acima, é possível compreender, por um lado, sua valorização em termos de autoimagem e, por outro, a tragédia em termos da possibilidade ou concretização de sua perda. $\mathrm{O}$ câncer é umas das doenças que mais alteram a imagem corporal, imagem essa que o sujeito não deseja. $O$ câncer de mama significa uma mutilação para as mulheres, visto que o seio é um dos principais representantes da feminilidade. Contudo, o surgimento do câncer de mama causa sequelas traumáticas para a mulher que vão além da doença em si.

\section{$O$ corpo e o câncer de mama}

De acordo com o INCA (Instituto Nacional de Câncer), o câncer de mama é o tipo de câncer que mais acomete as mulheres em todo o mundo. "O câncer é o nome dado a um conjunto de mais de 100 doenças que têm em comum o crescimento desordenado (maligno) de células que invadem os tecidos e órgãos, podendo espalhar-se (metástase) para outras regiões do corpo". $\mathrm{O}$ câncer de mama acomete uma ou as duas mamas e, por vezes, as axilas, manifestando-se no início como um nódulo. Esse tipo de câncer é mais comum em mulheres acima de 35 anos e, embora possua um bom prognóstico quando identificado no início, é considerado um problema de saúde pública (INCA, 2014).

Observando dados do Ministério da Saúde (2002), é notável que a formação do câncer é lenta e pode levar vários anos para que uma célula se propague e origine um tumor palpável. O tratamento cirúrgico tem como objetivo extrair o tumor ou fazer a biópsia, proporcionando o controle da área afetada. De acordo com Bland e Copeland (1994) as cirurgias podem ser de dois tipos: conservadora (realizada para retirada de tumores pequenos, preservando a mama) ou radical (mastectomia, indicada quando o tumor se encontra em estágio avançado).

Mesmo quando só se retira o tumor e se conserva a mama, percebe-se a angústia e o medo ocasionado pela doença, que afeta mais que um órgão: o seio é tido pela mulher como representante da sua feminilidade. "No imaginário social, a mama costuma ser associada a atos prazerosos - como amamentar, seduzir e acariciar -, não combinando com a ideia de ser objeto de uma intervenção dolorosa, ainda que necessária" (GOMES; SKABA; VIEIRA, 2002, p. 200-201).

A retirada cirúrgica do seio tem um viés da atualização da castração primordial. Se a menina se estrutura simbolicamente em meio a fantasias de amputação ao reconhecer as diferenças anatômicas entre gêneros, a cirurgia seria a atualização da castração, que estivera presente em termos virtuais (SOARES, 2008).

O medo da morte (concomitante ao sofrimento da perda de um órgão que representa sua feminilidade) e o receio de perder o parceiro (devido ao comprometimento da sua sexualidade durante o tratamento) são alguns fatores que acometem a vida dessas mulheres que necessitam de apoio.

Dias e Durà (2001) consideram a família um "agente de extensão" no tratamento oncológico, tornando-se alicerces de suporte psicossocial. As preocupações e os medos são compartilhados pelos mais próximos, havendo um sentimento de impotência diante da nova realidade. Portanto, para uma equipe de saúde, a família pode ser considerada como "pacientes de segunda ordem", visto que a dinâmica dessa família 
muda, sofrendo com os impactos emocionais. Em certo sentido, o câncer de mama é um problema da família como "unidade de tratamento", e não só da mulher. Isso, porque a família se constitui como "prestadora de cuidados" à paciente, exercendo seu papel social.

Ao retirar o seio, a mulher apresenta uma ferida narcísica, ao ter o câncer sob uma ameaça de morte real. Dunley $(2007$, p.333) associa a "mastectomia como uma castração feminina no real do corpo [...] uma vez que essa 'castração' também deixa vestígio, o outro seio, que lembra continuamente a perda do outro, o câncer, a morte".

Atualmente, existem vários recursos de cirurgia plástica que tentam minimizar as alterações físicas deixadas pela mastectomia. A reconstrução da mama tenta devolver a essas mulheres seus desejos e satisfações. Por isso, é importante que a demanda seja da própria mulher, para que sua implicação seja efetiva. Afinal, o que está em questão são os anseios e frustrações dessa nova mulher, que vem tentando outras significações para se reconstituir como mulher.

\section{O corpo tratado pela psicologia oncológica}

A atuação da Psicologia, na oncologia, só surgiu na década de 1970, e vem desempenhando um considerável papel no tratamento do câncer, onde interfere de forma positiva no prognóstico destes pacientes. Para Gimenes (1994), a Psico-oncologia possui quatro níveis de intervenção:

O nível primário visa os estilos de vida do indivíduo, o estresse cotidiano e o comportamento alimentar. É importante que o sujeito consiga elaborar o estresse da nova vida cotidiana. Inclusive, percebendo a sobrecarga física e emocional.

$\mathrm{O}$ nível secundário estaria ligado à promoção de saúde voltada para questões relacionadas mais diretamente ao câncer, no sentido de alertar a população para distinguir hábitos saudáveis dos prejudiciais, por meio de campanhas e palestras. Ou seja, informar a população sobre os métodos preventivos de diversos tipos de câncer, mostrando que os exames periódicos são imprescindíveis para a prevenção e detecção precoce, além de capacitar os profissionais para a atuação nesse sentido.

O nível terciário envolve intervenções realizadas no tratamento, visando a uma maior aceitação ao tratamento por parte do paciente. Deve-se promover o conhecimento das prescrições de tratamento ao indivíduo diagnosticado com câncer, impulsionando explicitamente o enfrentamento da doença.

Os cuidados paliativos são as intervenções realizadas na fase terminal, envolvendo aspectos como: necessidades emocionais da pessoa, apoio à família e à própria equipe de saúde envolvida com o paciente terminal. Diante disso, a família precisa de acolhimento para conseguir lidar com os sentimentos relacionados à perda. Também é preciso oferecer um tratamento que respeite a integridade do paciente, assim como oferecer um suporte para equipe de saúde envolvida.

Na concepção de Carvalho (2002), a atuação do psicólogo oncológico, tanto no apoio, aconselhamento, reabilitação, quanto na clínica individual/grupal, pode facilitar a transmissão do diagnóstico, a melhor aceitação dos tratamentos, proporcionando melhor qualidade de vida e, no caso de paciente em fase terminal, uma melhor maneira de morrer.

Segundo Gimenes (1994), as intervenções psicológicas são relevantes, pois têm a possibilidade de ajudar o paciente a lidar com os aspectos que abrangem o diagnóstico de uma doença que está relacionada ao sofrimento, medo da morte, mutilação e solidão.

A forma que a mulher enfrenta o câncer de mama é significativa no tratamento e não é um processo fácil. Afinal, ela precisa reconstruir valores e ressignificar essa perda. E a psicologia vem contribuir, na tentativa de promover melhor condição de vida, auxiliando nesse manejo, possibilitando maior adaptação imposta pela doença.

Cabe a nós, analistas, saber dirigir, manejar o tratamento
visando a acolher o sofrimento deste corpo que lateja,
inflamado pela lesão, pela constituição de um espaço
de continência de sua angústia, bem como um espaço
simbólico que suporte a premência do organismo
doente e que lhe dê legitimidade para que, por "doses de
conta-gotas", o corpo pulsional possa se fazer presente
no discurso do paciente (TEIXEIRA, 2006, p.32).

Dessa maneira, a psico-oncologia se apresenta como um importante método de promoção à saúde. Enquanto ciência, possui a capacidade não só de avaliar os processos psicológicos envolvidos com o fundamento e desenvolvimento do câncer, como também proporcionar melhoria na qualidade de vida, avaliando e identificando o papel psicossocial na prevenção, na doença e no tratamento.

Segundo Costa Jr. (2001, p.02), a psicologia oncológica é um "campo interdisciplinar da saúde que estuda a influência de fatores psicológicos sobre o desenvolvimento, o tratamento e a reabilitação do câncer". O autor ressalta que o objetivo do trabalho do psicólogo na área oncológica é perceber os fatores psicossociais e contextos ambientais dos pacientes em que a intervenção psicológica pode contribuir a fim de melhorar a condução do tratamento. Dito de outra forma, a atuação do psicólogo na oncologia busca:

Manter o bem-estar psicológico do paciente, identificando e compreendendo os fatores emocionais que intervêm na sua saúde. Outros objetivos do trabalho desse profissional são prevenir e reduzir os sintomas emocionais e físicos causados 
pelo câncere seus tratamentos, levar o paciente a compreender o significado da experiência do adoecer, possibilitando assim ressignificações desse processo (VENÂNCIO, 2004, p.58).

Além disso, o tratamento específico das mulheres que sofrem de câncer de mama deve consistir na "recuperação e/ou preservação da qualidade de vida. Fazse necessário apoio para readquirir bom relacionamento familiar, desempenho profissional, capacidade de elaborar planos e visualizar perspectivas" (BARROS, 2008, p. 43).

Brant (2001) aponta para o enfoque psicanalítico voltado para as condições subjetivas da paciente, da sua família e do seu contexto social, na organização psíquica e na experiência da doença, ou seja, no processo do adoecer. $\mathrm{O}$ câncer continua sendo uma doença que confronta a morte, a despeito dos avanços das pesquisas em saúde. O profissional enfrenta questões da sexualidade, da castração e do trauma. Além disso, o próprio diagnóstico consiste num entrave para o sujeito se organizar subjetivamente, encontrando o desamparo.

Peres e Martins (2000) sugerem que o trabalho do psicólogo com pacientes com câncer seja multidisciplinar, voltado para o paciente e os membros de sua família, objetivando oferecer uma escuta à família para falarem dos sentimentos em relação à doença. É importante mencionar que o psicólogo oncológico deve reforçar os laços familiares desse paciente, para que se sinta emocionalmente mais fortalecido.

No trabalho com a equipe de saúde, é imprescindível a interação entre todos os profissionais da equipe envolvidos no tratamento do câncer de mama para que se possa obter um bom resultado, compreendendo todos os aspectos implicados no adoecimento. Moraes (1994) reforça o papel do psicólogo no cuidado oncológico junto com a equipe multidisciplinar e destaca a pluralidade do campo, cheio de abordagens. Desde as psicodramáticas, até as abordagens psicanalíticas:

A escolha de qual será a melhor abordagem a ser utilizada deve ser calcada no tipo de grupo (de ambulatório ou de enfermaria, homogêneo ou heterogêneo, aberto ou fechado), sobre o objetivo (breve, de médio ou longo prazo) e sobre outras variáveis (informativo, de preparo para cirurgia ou para terapia, etc.) (VENÂNCIO, 2004, p.59).

A perda do seio está no "registro da carne (culpa), no registro do corpo (e da pulsão), no registro das relações com o objeto, no registro dos ideais e, portanto, do narcisismo, mas principalmente no registro simbólico da castração" (DUNLEY, 2007, p. 335). Por isso, precisamos compreender a singularidade de cada mulher, pois cada uma tem a sua representação do seio e a mastectomia configura-se de diferentes formas no nível narcísico, assim como a dor da perda do seio no processo de castração e a própria constituição da feminilidade.

\section{Concluindo}

A sociedade consumista cria padrões de beleza, mas o corpo ganha uma representação única para cada mulher. Muitas, por não conseguirem consumir esse ideal de corpo, sentem-se frustradas por não apresentarem a imagem desejada. Compreendemos, no entanto que essa imagem corporal é uma constituição inconsciente, construída desde a infância.

Dessa forma, os fundamentos psicanalíticos trouxeram grandes contribuições para a compreensão do processo da imagem na formação da feminilidade. $\mathrm{O}$ cuidado com a aparência ultrapassa uma falta real do corpo, que inconscientemente simboliza a castração feminina.

Freud (1905), em seus estudos sobre sexualidade infantil, coloca a mulher na condição de castrada. Sendo assim, a feminilidade decorre do processo de elaboração psíquica do posicionamento da criança diante do complexo de castração e complexo de Édipo. $\mathrm{O}$ investimento narcísico que a mulher faz em seu corpo, atualmente, torna-o objeto de desejo e satisfação sexual. Nesse culto ao corpo, a mulher vive sua sexualidade ancorada na feminilidade, gozando nessa relação narcísica e ao mesmo tempo sendo escrava desse corpo.

Contrapondo-se a essa vaidade, a doença que mais afeta as mulheres em todo o mundo é o câncer de mama, visto que é vivenciado com um intenso conflito físico e psicológico, desde o diagnóstico. O seio é o primeiro objeto de amor e de relação com o mundo do bebê. É o símbolo de desejo e identidade feminina que auxilia na constituição da sexualidade, onde a mulher reconhece sua feminilidade. A mutilação remete a uma falta, uma castração que causa insatisfação com o corpo, uma perda de identidade, afetando as relações sociais e sua própria feminilidade.

O modo de lidar com o câncer de mama entre as pacientes é peculiar, justamente pela relação que cada uma tem com a doença, e o tratamento se dá também por influência do contexto social e familiar. A família desenvolve um papel de suporte psicossocial importantíssimo no tratamento, contribuindo para o enfrentamento da doença.

No decorrer deste trabalho, foi possível perceber a importância da atuação do psicólogo no tratamento de pacientes com câncer e o cuidado que se deve ter com as intervenções para ser acolhedor sem ser invasivo. Cabe ao psicólogo oncológico estender a mão, acolher, escutar suas queixas e necessidades, ter uma boa comunicação com o paciente e com a equipe multidisciplinar, compreender o sujeito como um ser complexo.

Diante de tudo isso, foi possível pensar na atuação 
do psicólogo visando à ressignificação da angústia dessas mulheres, além de oferecer uma melhor qualidade de vida. Ao mesmo tempo revela-se importante perceber a complexidade da feminilidade, já que ser mulher é um enigma que se esclarece por aquilo que não é.

\section{Referências}

BARROS, A. C. S. D. Câncer de mama. In: Temas em psico-oncologia. São Paulo: Summus, 2008.

BASTOS, L. A. M. Eu-corpando: o ego e o id em Freud. São Paulo: Escuta, 1988

BLAND, K. I; COPELAND, E. M. A mama: tratamento compreensivo das doenças benignas e malignas. São Paulo: Manole, 1994.

CARVAlHO, M. M. Psico-oncologia: história, características e desafios. Psicol. USP, São Paulo, v.13,n.1,2002 . Disponível em: <http://www.scielo. br/scielo.php?script $=$ sci arttext\&pid $=$ S010365642002000100008\&lng $=$ en $\&$ nrm $=$ iso $>$ Acesso em 23 abr. 2015

COSTA, J. F. O vestígio e a aura: corpo e consumismo na moral do espetáculo. Rio de Janeiro: Garamond, 2004

COSTA JR, Á. L. O papel da psicologia no atendimento a crianças com câncer. 2001 .

DIAS, M.R \& DURÀ, E. Territórios da Psicologia Oncológica. Climepsi Editores,

2001.

DEL PRIORE, M. Corpo a corpo com a Mulher. Pequena história das transformações do corpo feminino no Brasil. São Paulo: SENAC, 2000.

DEL PRIORE, M. Histórias do cotidiano. São Paulo: Contexto, 2001.

DUNLEY, G. Grupos com pacientes mastectomizadas: Aplicações da psicanalise no trabalho institucional. In: MELLO FILHO, J. Grupo e corpo: psicoterapia de grupo com pacientes somáticos.São Paulo: Casa do Psicólogo, 2007.

FREUD, S. (1901-1905). Um caso de histeria, Três ensaios sobre sexualidade e outros Trabalhos.In:Edição Standard Brasileira das Obras Psicológicas Completas de Sigmund Freud Volume VII. Rio de Janeiro: Imago Editora. 2006.

(1914). Sobre o narcisismo: uma introdução, Vol. 14. Obras psicológicas completas de Sigmund Freud: edição standart brasileira. Rio de Janeiro: Imago, 1996.

(1925). O ego e o id. In: Standard Brasileira das Obras Completas de Sigmund Freud. Rio de Janeiro: Imago, 1996. Vol. XIX

(1925). Algumas consequências psíquicas da distinção anatômica entre os sexos.In:Standard Brasileira das Obras Completas de Sigmund Freud. Rio de Janeiro: Imago, 1996. Vol. XIX

(1933). Feminilidade. In: Standard Brasileira das Obras Completas de Sigmund Freud. Rio de Janeiro: Imago, 1996. Vol. XXII

GIMENES, M. G. G. Definição, foco de estudo e intervenção. In: Carvalho, M. M, M. J. Introdução à Psiconcologia. São Paulo: Editorial Psy II, 1994.

GOMES, R., SKABA, M. M. V. F. \& VIEIRA, R. J. S. Reinventando a vida: proposta para uma abordagem sócio antropológica do câncer de mama feminina. Caderno de Saúde Pública, 2002. Disponível em: $<$ http://www. scielosp.org/pdf/csp/v18n1/8156>. Acesso em: 23 mai.2015

INCA (INSTITUTO NACIONAL DE CÂNCER). Disponível em: <http:// www1.inca.gov.br/conteudo_view.asp?id=322> Acesso dia 22 fev.2015

LE BRETON, D. Adeus ao corpo: antropologia e sociedade. Campinas, SP: Papirus, 2003.

MINISTÉRIO DA SAÚDE. Secretaria Nacional de Assistência à Saúde. Instituto Nacional do Câncer. Falando sobre o câncer de mama. Rio de Janeiro, 2002
MORAES, M. C. O paciente oncológico, o psicólogo e o hospital. In: Carvalho, M. M, M. J. Introdução à Psiconcologia. São Paulo: Editorial Psy II, 1994.

NÁSIO, J. Lições sobre os sete conceitos cruciais da Psicanálise. Tradução de Vera Ribeiro. Rio de Janeiro: Jorge Zahar, 1993.

PERES, R. S; MARTINS, E. J.S. Ressaltando os aspectos psicológicos em uma proposta de atendimento psicossocial a pacientes oncológicos. Revista Psico, Porto Alegre, 2000.

PROMMIER, G. A exceção feminina: os impasses do gozo. Tradução de Dula P. Duque Estrada. Rio de Janeiro: Jorge Zahar, LTDA, 1987.

SOARES, R. G. Aspectos Emocionais do Câncer de Mama. Revista Virtual de Psicologia e da Saúde, 2008. Disponível em: $<$ http://www.sbpo.org. br/_newsletter/boletins/boletim_julho_agosto_setembro_2009/cancer_de_ mama.pdf>. Acesso em: 17 abr. 2015

TEDESCO, J. J. A. e CURY, A. F. Ginecologia Psicossomática. São Paulo: Atheneu, 2007.

TEIXEIRA, L.C. Um corpo que dói: considerações sobre a clínica psicanalítica dos fenômenos psicossomáticos. Latin-AmericanJournalof Fundamental PsychopathologyonLine, VI. Disponível em: <http://www. fundamentalpsychopathology.org/uploads/files/latin american/v3 n1/um corpo_que_doi.pdf> Acesso dia 09 mai.2015.

VENÂNCIO, J. L. Importância Da Atuação Do Psicólogo No Tratamento De Mulheres Com Câncer De Mama. Revista Brasileira de Cancerologia, 2004. Disponível em:

$<$ http://www.inca.gov.br/rbc/n 50/v01/pdf/revisao3.pdf $>$ Acesso em: 18 abr.2015 